\title{
Erratum to: Evaluation of add-on therapy of sitagliptin in Japanese patients with type 2 diabetes under insulin therapy
}

\author{
Tomoko Nakagami $\cdot$ Risa Ide $\cdot$ Naoko Iwasaki $\cdot$ Makiko Ogata \\ Junko Oya $\cdot$ Mari Osawa $\cdot$ Nobue Tanaka $\cdot$ Hiroko Takaike $\cdot$ Asako Sato $\cdot$ \\ Junnosuke Miura $\cdot$ Yasuko Uchigata
}

Published online: 28 February 2014

(C) The Japan Diabetes Society 2014

\section{Erratum to: Diabetol Int}

DOI 10.1007/s13340-013-0155-6

In our published paper, there were two errors to be corrected as follows.

In line 11 of first paragraph in Discussion section, "bolus insulin $>15$ units per day" should be "bolus insulin $\geq 15$ units per day". The last sentence of Discussion section should be "In conclusion, add-on sitagliptin may be a new therapeutic option in patients with type 2 diabetes with inadequate glycemic control by insulin therapy, possibly using bolus insulin dose of over 15 units per day".

The online version of the original article can be found under doi:10.1007/s13340-013-0155-6.

T. Nakagami $(\bowtie) \cdot$ R. Ide $\cdot$ N. Iwasaki $\cdot$ M. Ogata $\cdot$ J. Oya

N. Tanaka $\cdot$ H. Takaike $\cdot$ A. Sato · J. Miura $\cdot$ Y. Uchigata Diabetes Center, Tokyo Women's Medical University School of Medicine, 8-1 Kawada-cho, Shinjuku-ku, Tokyo 162-8666, Japan

e-mail: nakagami@dmc.twmu.ac.jp

M. Osawa

Institute of Geriatrics, Tokyo Women's Medical University, Tokyo, Japan

A. Sato

Laboratory Medicine, Tokyo Women's Medical University,

Tokyo, Japan 